\title{
Cadastro: \\ Função Básica de Administração de Pessoal
}

\section{PEDRO AUGUSTO CYSNEIROS}

Técnico de Administração

O CADASTRO É FUNÇÃO BÁSICA DE ADMINISTRACCÃO DE PESSOAL, como dispõe o art. 2..$^{\circ}$ do Decreto n. ${ }^{\circ} 67.326$, de 1970 , que instituiu o Sistema de Pessoal Civil (SIPEC). A conclusão idêntica chegará, também, qualquer executivo se analisar a Administração de Pessoal. Sem elementos fácticos, sem dados objetivos e fidedignos, ele verá não ser possível tomar uma decisão responsável em matéria de Administração de Pessoal. Sem ele (Cadastro) poderá um dirigente decidir acertadamente, mas por mero acaso ou com lastro em grande visão e experiências pessoais.

Contudo, esse é um procedimento nitidamente amadorista. No atual estágio de desenvolvimento científico e tecnolóaico, não é racional deixar-se ao acaso o acerto ou o erro, o ganho ou a perda.

Administração, quer no setor público, como no particular, não é um jogo, para estar sujeita aos caprichos da sorte.

Há que se pautar por normas técnicas e objetivas.

Empenha-se o Governo em promover o bem-estar do povo e o desenvolvimento nacional. A inter-relação entre esses objetivos e recursos humanos adequados, quer nas atividades privadas como na administração pública, é mais do que óbvia. 
Não poderemos pensar em reforma administrativa e na utilização de moderna metıdologia sem uma definição precisa dos recursos humanos existentes no serviço público.

O instrumento que nos permitirá obter essa definição, ou melhor, identificar o universo humano no Serviço Público Civil Federal Brasileiro é, sem dúvida alguma, o Cadastro.

Não o Cadastro anacrônico, inerte e relegado a último plano. Não o Cadastro chefiado por funcionário despreparado e mantido (?) por servidores julgados ineficientes, em outros setores, nem o Cadastro usado como refúgio de pessoal inaproveitável em outros misteres.

O Cadastro de que precisamos é o Cadastro moderno, dinâmico e atuante. Aquele voltado para o aperfeiçoamento da técnica de registros. Aquele que armazena dados e não, apenas, entulha (ou empilha) fichas, documentos, boletins e Diários Oficiais. Aquele que registra fatos e elementos, diuturnamente, não com o fim de guardá-los, mas servindo como organismo de informação e, nessa qualidade, sendo a origem de uma decisão ou ação administrativa.

O Cadastro a ser implantado no Departamento Administrativo do Pessoal Civil - DASP, por conseguinte, possui conceituação ampla e se guarda alguns pontos de contato com o antigo é apenas pelo fato de não haver necessidade de mudar o que está certo. Não se pretende demolir: o que se deseja é reformar e aperfeiçoar. O novo Cadastro não estará confinado ao âmbito das antigas Seções ou Divisões de Cadastro. Ele abrange qualquer setor que, por força da aplicação do princípio da divisão racional do trabalho, faça registro sobre cargos, empregos ou sobre qualquer aspecto da vida funcional dos servidores e, também, dos que prestam serviços à administração a qualquer título.

O Cadastro, pois, não se confina a uma única subdivisão administrativa. Ele não está contido nos limites de uma área física. Esta é a filosofia que norteia o Cadastro. Não é uma área organizacional mas uma área funcional. Dele fazem parte dados ou registros relativos a cargos, empregos, encargos, gratificações, vantagens ou a qualquer aspecto da vida funcional do servidor.

Por isso, 
CADASTRO DE PESSOAL É O CONJUNTO DE REGISTROS SISTEMÁTICOS E ATUALIZADOS DO NÚMERO DE CARGOS, FUNÇÕES E EMPREGOS DA ADMINISTRAÇÃO PÚBLICA (OU DE UMA EMPRESA), ASSIM COMO DE DADOS FUNCIONAIS E PESSOAIS DOS RESPECTIVOS OCUPANTES. ABRANGE, TAMBÉM, A PRESTAÇÃO DE SERVIÇOS RETRIBUÍDA MEDIANTE RECIBO OU A LOCAÇÃO DE SERVIÇOS.

Sentindo a necessidade de contar com órgãos de informa. ções apropriados, baixou o Governo o Decreto n. 72.255 , de 11 de maio de 1973, instituindo o Subsistema de Cadastro, fixando diretrizes e a respectiva estrutura global. Delegou, também, competência ao DASP para baixar instruções, dispondo, entre outros assuntos, sobre a estrutura e o funcionamento do Subsistema e - releva acentuar - para definir o conteúdo do Cadastro Central Permanente e dos Cadastros Setoriais e Seccionais.

Como visto, se de um lado o Cadastro compreenderá todos os registros que lhe são necessários - muitas vezes difundidos em áreas físicas diversas - de outro institucionalizou-se, criando não apenas normas mas um Subsistema incumbido de coletar, registrar e processar os dados - buscando-os onde quer que eles se encontrem.

Sem querer hiperestimar a tarefa, o Cadastro requer planejamento cuidadoso, onde os mais variados aspectos técnicos devem ser considerados. Não é tarefa simples ou de mera rotina. Enormes obstáculos têm que ser superados. O planejamento precisa ser maleável para poder adaptar-se ao dinamismo dos fatos e atos a registrar, os quais se transmudam quase cotidianamente em uma época de reformas e aperfeiçoamentos que vimos vivendo há alguns anos.

Cuidou, pois, a Instrução Normativa DASP n. ${ }^{\circ} 12$, de 20 de julho de 1973, principalmente, de definir o conteúdo dos Cadastros: Central, Setoriais e Seccionais. Preocupa-se mais essa Instrução em definir o conteúdo dos Cadastros, deixando - propositadamente - de fixar normas rígidas sobre a forma de ser feito o registro. Assim foi por inexistir uma forma ideal única de fazer-se o registro. A forma ideal depende de fatores conjunturais e ecológicos. Ela deve adaptar-se às condições e dimensões locais. Queremos - por ser o mais importante - formular o seguinte "Axioma do Cadastro" : 
"os registros devem ser feitos de forma completa

e correta e mantidos rigorosamente em dia".

Usamos o termo "axioma" no seu estrito sentido matemático : uma verdade evidente que não precisa ser demonstrada.

Com o envio do Manual de Cadastro aos Órgãos Setoriais e Seccionais do Sistema de Pessoal Civil, iniciou o DASP a execução de nova fase do planejamento global, lançando bases concretas para que se possa fazer uma real e completa reforma na Administração de Pessoal. Estará, assim, ao término da coleta, em condições de fornecer ao governo, prontamente, os informes necessários à formulação e reformulação de políticas e à tomada de decisões. Propiciará, assim, o Cadastro sejam alcançados - nessa área de atuação - os objetivos governamentais de se profissionalizar e dignificar o funcionalismo público.

É o Cadastro ambivalente. Não é somente útil à ação dos administradores e do Governo. É também essencial à defesa dos legitimos direitos do funcionalismo. Evita sejam, por comodismo, omissão ou ignorância, postergados ou esquecidos direitos dos servidores. Algumas vantagens e gratificações devem ser concedidas "ex-officio". Atualmente, o pagamento delas fica "mofando" a espera de requerimento inteiramente desnecessário e descabido, contribuindo essa praxe tão-somente para burocratizar e tumultuar a ação dos órgãos de pessoal. O Cadastro atuante impedirá isso.

Não ficará mais o funcionário esperando meses para receber a sua gratificação adicional ou para tê-la reajustada. Não esperará, como tem ocorrido, anos para ter a sua promoção decretada, fato este que tanto desperdício de tempo tem acarretado, provocando a revisão em cadeia de diversos atos administrativos e interferindo, sem razão (pois poderia ter sido evitado), nas atividades de Ministros de Estado e até do Presidente da República.

Ao solicitar aposentadoria, por exemplo, o pedido poderá ser decidido sem delongas, porquanto todos os dados já estarão apurados e registrados. Não será mais, como vem acontecendo agora em muitos casos, quando somente na hora do pedido é apurado o tempo de serviço do funcionário.

Se examinarmos a Instrução Normativa n. 12 , de 20 de julho de 1973, inclusive os seus anexos, constataremos ter o $\mathrm{Ca}$ dastro atuação em três niveis, ou áreas administrativas, a saber:

R. Serv. públ., Brasília, 109 (3) jul./set. 1974 


\section{9) local \\ 2. ${ }^{\circ}$ ) setorial e \\ 3.) central,}

considerada esta última como a área correspondente ao cimo da pirâmide governamental .

Desta forma, será o Cadastro útil e utilizável, desde as funções operativas mais simples da administração de pessoal até o controle, o planejamento e a formulação de diretrizes.

Fará o corriqueiro registro da freqüência do funcionário, mas de tanta repercussão na vida funcional, e fornecerá elementos ao Governo para estabelecer novas diretrizes e adotar novas soluções.

Em regra, devem ser apresentadas ao Governo soluções alternativas ou opções, que precisam ser comparadas e ter avaliadas as suas repercussões. Imprescindível, assim, sejam elas acompanhadas de dados ou elementos concretos, fidedignos e de elevada confiabilidade.

Esta é a função, ou melhor, o objetivo principal do Cadastro Central Permanente : fornecer ao Governo, quando algum assunto relativo à administração de pessoal esteja em pauta, os elementos necessários ao julgamento de cada opção; quantos e quais serão os funcionários abrangidos; onde eles se encontram e qual o custo - se, é claro, a matéria acarretar despesa.

Para atingir esse objetivo, adotou-se, na configuração do CADASTRO, o chamado processo do planejamento sólido, constituindo-se, este, apenas, no pensamento ordenado.

Esse processo, como todos sabem, envolve cinco etapas básicas, resumidas da forma seguinte:

1) Identificar e definir o problema;

2) Determinar as soluções possíveis (nesta etapa, as idéias e as hipóteses são necessárias);

3) Coligir e analisar fatos, obedecendo a uma direção definida, pois do contrário ela jamais acabaria; 
4) Determinar a solução. Isto é, tomar a decisão. Vale lembrar que nem sempre a solução perfeita ou quase perfeita é a escolhida. Os fatos, as disponibilidades e a exeqüibilidade naquele momento determinam a decisão.

5) Agir para executar a solução adotada.

No concernente ao trabalho do Cadastro de Pessoal, as quatro primeiras etapas já foram vencidas.

Definiu-se o objetivo do Cadastro e o seu propósito. Decidiu-se o que se devia registrar e, depois, como registrar e o método a ser utilizado no registro. Feito isso, elaborou-se os meios de captação de dados, já sabido, lógico, ser o método de computação eletrônica de dados, nos quais se contém a decisão do que pedir, como pedir e a quem pedir. Procurou-se nessa decisão simplificar o máximo possível, sem comprometer o objetivo final e a eficiência da execução do método escolhido.

A quinta etapa foi iniciada com a remessa do MANUAL DE CADASTRO aos Órgãos Setoriais e Seccionais do SIPEC. Outras atividades de ordem interna estão em plena execução. No caso específico do CADASTRO, esta etapa é contínua e, teoricamente, jamais acabará, porquanto a implantação do CADASTRO e a sua constante atualização de certa forma, constituem forma de ação permanente para executar a solução adotada.

É mister, é curial, é imprescindível contar o DASP com a colaboração integral de todos - começando pelos dirigentes dos órgãos integrantes do SIPEC - a fim de ter o mais rapidamente possível - e de forma eficaz - concluído o Cadastro Central Permanente.

É bom lembrar, contudo, estar o funcionamento do Cadastro Central dependente da montagem e execução dos Cadastros Setoriais e Seccionais. Eles constituirão a pedra angular da administração do pessoal civil da União.

Mesmo requerendo muito esforço, deve-se fazê-lo; não como promoção de ninguém ou de nenhum órgão, mas em prol da eficiência do SERVIÇO PÚBLICO FEDERAL BRASILEIRO E DE SEU 